\title{
Mineração
}

\section{Utilização de sismógrafos de engenharia como ferramenta no controle de qualidade de acessórios de detonação não elétricos}

\author{
(Quality control of nonelectric MS delay detonator with \\ engineering seismograph)
}

\author{
Caetano Dallora Neto \\ Engenheiro de Minas, Mestre em Geociências.E-mail: caetano.dallora@gmail.com \\ Gilda Carneiro Ferreira \\ Engenheira de Minas/DGA/IGCE/UNESP.E-mail: gildacf@rc.unesp.br \\ João Carlos Dourado \\ Geólogo/DGA/IGCE/UNESP.E-mail: jdourado@rc.unesp.br
}

\begin{abstract}
Resumo
Nesse artigo, são apresentados os trabalhos realizados com o objetivo de verificar se a elevada dispersão dos valores de velocidade de partícula obtidos durante monitoramentos de vibrações decorrentes de desmontes de rocha com a utilização de explosivos, em mineração localizada no município de Limeira (SP), vinculava-se a variações nos tempos dos elementos de retardo dos acessórios de detonação em relação aos nominais. Os experimentos foram realizados em janeiro e junho de 2004. O procedimento adotado para estimar os tempos de retardo de acessórios de detonação não elétricos redundou em resultados que apresentam consistência, necessitando, porém, de estudos mais aprofundados. Os dados obtidos indicam a necessidade de considerar sua ocorrência quando da elaboração de planos de fogo, por suas implicações: ambientais, que inclui aspectos relativos à segurança e econômicas.
\end{abstract}

Palavras-chave: Vibração, acessórios de detonação, detonações.

\begin{abstract}
In this paper is presented studies whose main objective was to verify if the high dispersion of particle velocity values gotten during ground vibration monitoring of rock blasting in a mine located in the Municipality of Limeira, State of São Paulo, were related to the firing time variations in the nonelectric MS delay detonators, in relation to the nominal ones. The experiments were carried out in January and June 2004 and the adopted method to estimate the firing time of these detonators produced results that indicate consistence, but there is still a need for more detailed studies. The results of this study indicate the necessity to consider these variations when elaborating blasting designs, so that environmental impacts, such as safety and economical aspects, are attended to.
\end{abstract}

Keywords: Vibration, MS delay, detonations. 


\section{Introdução}

Durante os trabalhos de monitoramento de detonações em mineração produtora de calcário e argilito situada no município de Limeira, SP, nos períodos de dezembro de 1999 a dezembro de 2000 e de abril de 2003 a novembro de 2003, foram obtidos indicativos de que a elevada dispersão dos valores de velocidade de partícula obtidos em campo pudesse estar associada, ao menos em parte, a desvios nos tempos dos elementos de retardo em relação àqueles apontados pelo fabricante. Esses indicativos levaram à necessidade de realização de experimentos que possibilitassem sua determinação com os equipamentos disponíveis: sismógrafos de engenharia Blastmate III e Minimate Plus.

Partindo do princípio de que perturbações geradas em instantes distintos poderiam ser captadas e registradas por tais aparelhos, a concretização dos experimentos vinculava-se à sua operacionalização, que deveria atender aos quesitos de confiabilidade, segurança, praticidade e economicidade.

Deveria contemplar, ainda, o tipo específico dos elementos de retardo utilizados no empreendimento, quando ocorreram os monitoramentos de vibrações. Tais acessórios de detonação são do tipo não elétrico, constituído por tubete plástico de comprimento especificado e espoleta de retardo em uma de suas extremidades, com seu tempo vinculado ao desempenho do conjunto. Os tempos de retardo ali adotados são de 17 e 25 milissegundos na ligação entre minas e 250 milissegundos na iniciação da coluna de explosivos.

\section{Procedimentos experimentais}

Concebeu-se uma situação onde seriam realizados dois furos. Em um deles seria inserido um conjunto estopim/ espoleta simples com a função de, quando detonado, iniciar o acessório não elétrico de retardo a ele conectado e disparar o equipamento de registro. O outro abrigaria a extremidade do acessório não elétrico dotada de espoleta de retardo. A instalação do sensor, ou geofone, do sismógrafo de engenharia deveria se dar de maneira eqüidistante dos furos e com a menor distância possível, como forma de minimizar a possibilidade de ocorrência de descontinuidades no meio de propagação que pudessem distorcer os resultados.

Inicialmente tal experimento foi realizado em janeiro de 2004, tendo-se, como meio de propagação, o solo, pelas facilidades em sua execução. Os furos foram efetuados com trado manual de 1 " de diâmetro e trinta centímetros de profundidade. A distância adotada entre furos foi de 1,5 metros (df) e a distância entre eles e o geofone de 3,0 metros (d) (Figura 1). Os retardos utilizados foram de 25 milissegundos. $\mathrm{O}$ aparelho utilizado foi o BlastMate III, configurado em modo Normal (amplitude máxima de 254 $\mathrm{mm} / \mathrm{s}$ ) e freqüiência de amostragem de 1024 amostras por segundo. O geofone foi orientado ao furo que iniciaria o processo de registro e fixado por meio de pinos. O disparador foi configurado para atuar a amplitudes de 0,5 milímetros por segundo (Dallora Neto, 2004).

A possibilidade de danos causados ao tubete plástico do elemento de retardo não elétrico pelo calor liberado na queima do estopim, podendo ocasionar sua falha, levou à sua fixação, com fita adesiva, a distância de aproximadamente um centímetro entre eles.

Após alguns resultados insatisfatórios, decorrentes da superposição dos trens de onda originários das duas perturbações, em razão das características elásticas do meio de propagação, na forma como o experimento foi conduzido, e da baixa resolução dos registros, optouse por:

- Alterar as configurações do sismógrafo para o modo sensível (amplitude máxima de 31,7 mm/s) e freqüência de amostragem de 4096 amostras por segundo.

- Solidarizar à espoleta de retardo, dos acessórios não elétricos utilizados na ligação entre minas, uma espoleta simples. Esse procedimento justifica-se pela amplificação do sinal gerado em sua detonação, uma vez que a carga de explosivos de suas espoletas é reduzida quando comparada às das espoletas simples $n^{\circ} .8$ (Figura 2).

Os demais procedimentos foram mantidos.

\section{Análise e interpretação dos dados}

Foram realizados seis experimentos com conjuntos de espoleta simples e retardo de 25 milissegundos e quatro apenas com espoleta simples, em duas ocasiões. Em ambas, a instalação do geofone deu-se uma única vez, com a reutilização parcial dos furos. Procurando recompor sua conformação original, alterada pelas detonações, realizou-se o preenchimento com solo de 2/3 de sua profundidade, gradualmente compactado, e reexecução até a profundidade inicial.

Alguns resultados podem ser visualizados nas Figuras 3, 4 e 5. Os sismogramas mostrados foram realizados com a importação de dados do software BlastWare Series III para o Microsoft Excel 97.

Como pode ser constatado, os resultados apresentam similaridade, com registros referentes a dois conjuntos "espoleta simples/retardo” praticamente superpostos e o terceiro apresentando defasagem em relação a eles, indicando a ocorrência de desvios nos tempos de retardos. Em ambas as ocasiões obtiveram-se resultados semelhantes.

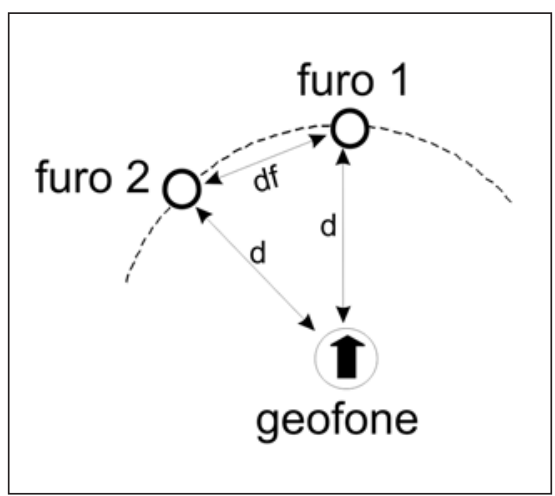

Figura 1 -Esquema de montagem do experimento. 


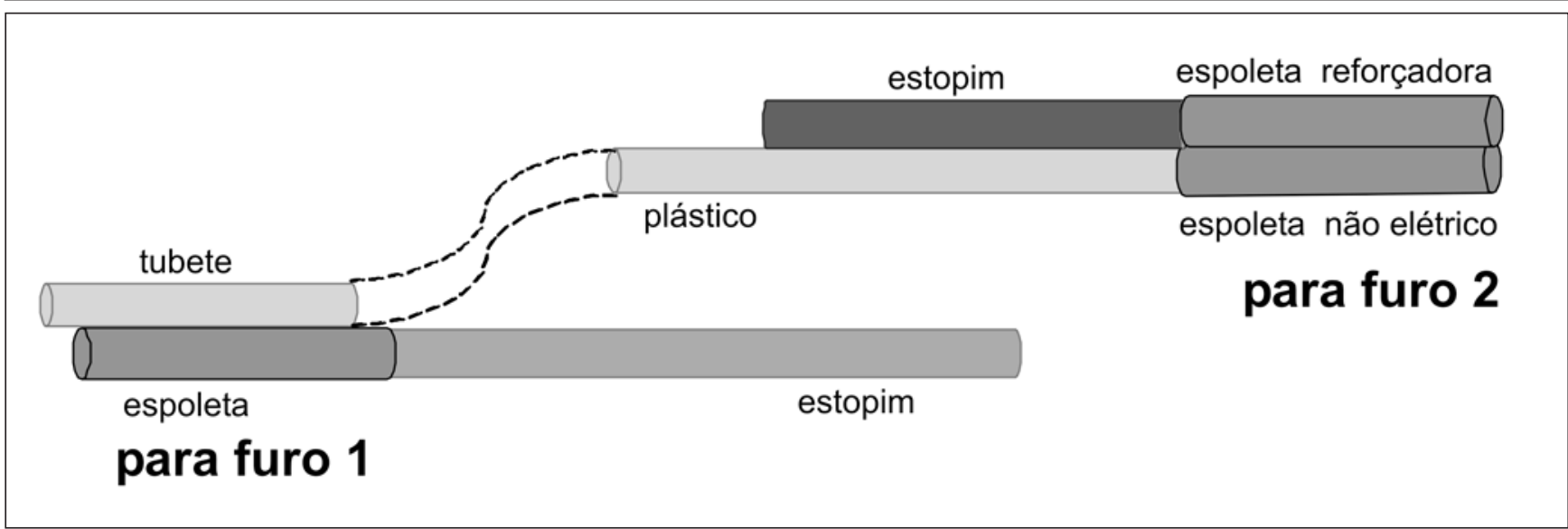

Figura 2 - Esquema de montagem dos conjuntos espoleta/estopim e não elétrico de retardo.

O artifício utilizado para a determinação dos tempos de retardo foi promover a deconvolução do sinal proveniente do registro do conjunto "espoleta simples/retardo" daquele originado pela espoleta simples, com a utilização dos dados provenientes, em cada ocasião, unicamente pelas espoletas simples (Figuras 6,7 e 8 ).

A deconvolução é um processo que, em última análise, tem o significado de um filtro aplicado ao sinal originado pelo conjunto "espoleta simples/retardo", dele expurgando o sinal proveniente da espoleta simples, com a obtenção da representação daquele provocado apenas pelo retardo, com poucas distorções, mantidas as referências de tempo.

No caso desse trabalho, a deconvolução foi realizada no domínio do tempo, o que corresponde, matematicamente, na divisão polinominal do vetor constituído pelo sinal digitalizado proveniente da espoleta simples/retardo pelo vetor do sinal digitalizado da espoleta simples.

As Figuras 9, 10 e 11 representam os resultados obtidos a partir dos procedimentos descritos, utilizando-se os dados constantes nos registros E 2 - espoleta simples - e R 3 - conjunto espoleta simples/retardo. Os pontos indicados através de setas nas Figuras 9, 10 e 11 indicam pontos homólogos da representação dos picos causados pela espoleta simples $n .^{\circ} 8$ e decorrente, exclusivamente, da espoleta de retardo, obtida atra-

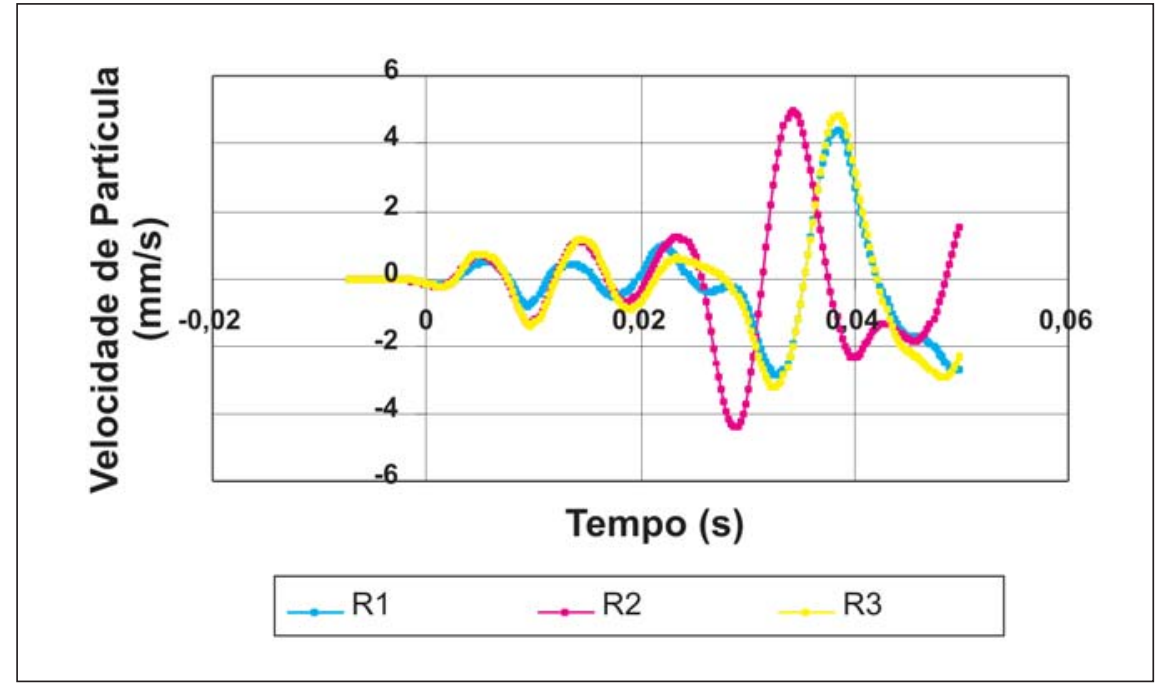

Figura 3 - Registros obtidos na componente transversal; eventos monitorados em 20/ 01/04 a partir de conjuntos compostos por espoleta simples e de retardo de $25 \mathrm{~ms}$.

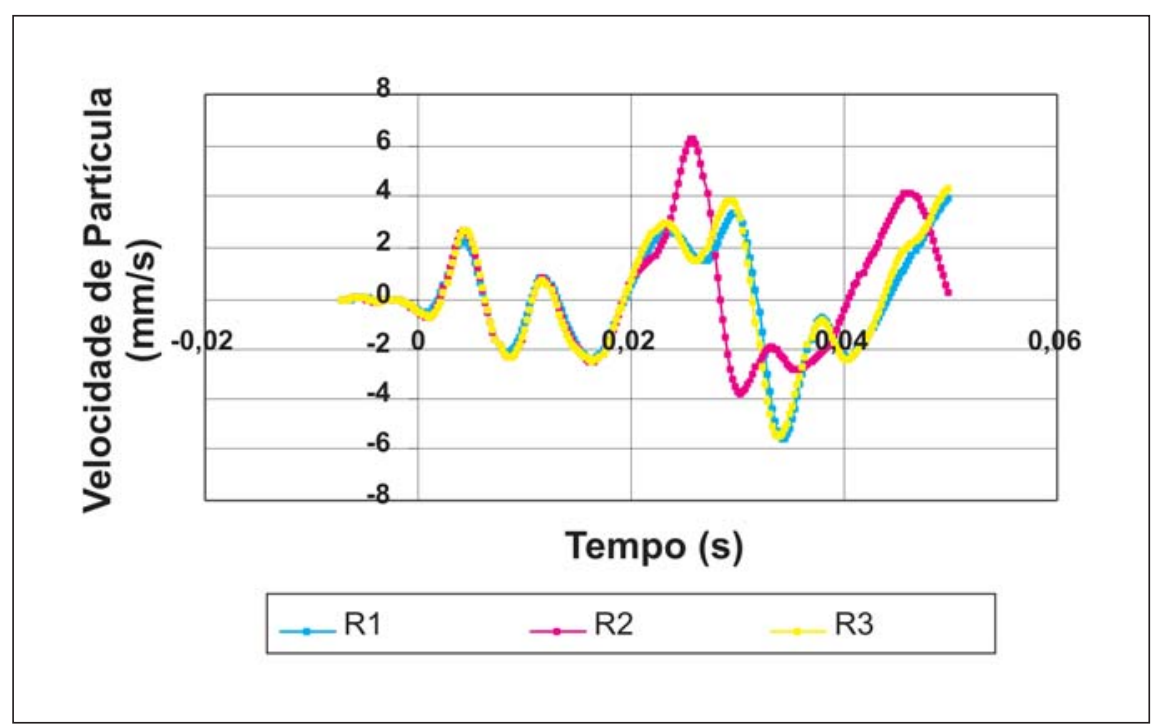

Figura 4 - Registros obtidos na componente vertical; eventos monitorados em 20/01/ 04 a partir de conjuntos compostos por espoleta simples e de retardo de $25 \mathrm{~ms}$. 
vés de deconvolução. O intervalo de tempo compreendido entre ambos é o considerado como o tempo de retardo.

Os valores obtidos para os acessórios de detonação com tempo de retardo nominal de 25 ms encontram-se na Tabela 1.

Em junho de 2004, novos ensaios foram realizados para a determinação de tempos de retardo em acessórios com tempos nominais de 17 milissegundos e 25 milisegundos, utilizados na ligação entre furos e 250 milisegundos, na iniciação da coluna de explosivos. Tais acessórios de detonação integravam lote obtido através da mesma aquisição daqueles utilizados em janeiro, tendo sido mantidos armazenados para essa finalidade.

Por suas características elásticas, o meio de propagação escolhido foi um maciço basáltico, sendo os furos realizados em um afloramento natural por meio de perfuratriz de impacto elétrica. Com 20 centímetros de profundidade e 19 milímetros de diâmetro, tais furos foram realizados à distancia de 50 centímetros um do outro. O geofone foi posicionado a 1,3 metros de distância de ambos os furos, orientado ao furo que iniciaria o processo de registro e fixado ao maciço através de pasta de gesso. A fim de melhorar as condições de propagação das perturbações geradas pelas detonações, os furos foram preenchidos com água antes de cada evento.

O aparelho utilizado foi o MiniMate Plus, com as mesmas configurações anteriormente descritas. Também foram mantidas as características de montagem dos conjuntos espoleta simples/não elétrico, exceto naquelas montagens onde foram utilizados acessórios não elétricos de coluna, de 250 milissegundos, que dispensam a utilização de espoleta reforçadora, dada a característica de sua carga explosiva. Para evitar a ejeção do conjunto espoleta simples/não elétrico, após a detonação da primeira carga explosiva, realizou-se sua fixação por meio de um anel plástico solidarizado ao maciço através de pasta de gesso.

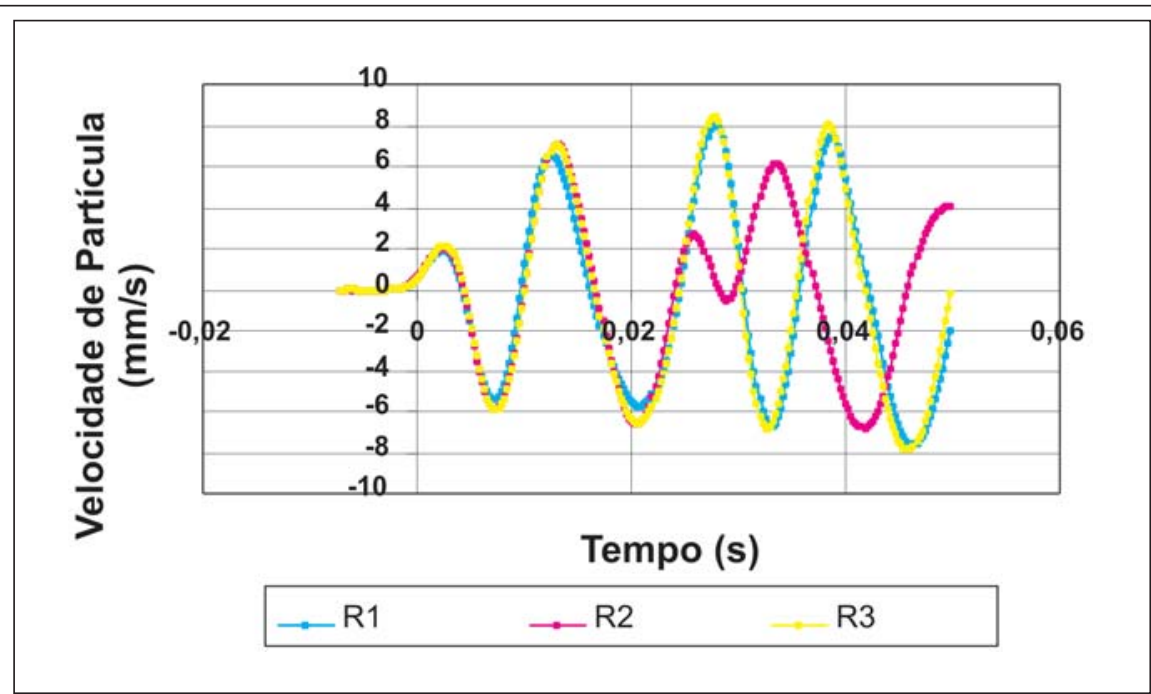

Figura 5 - Registros obtidos na componente longitudinal; eventos monitorados em 20/01/04 a partir de conjuntos compostos por espoleta simples e de retardo de $25 \mathrm{~ms}$.

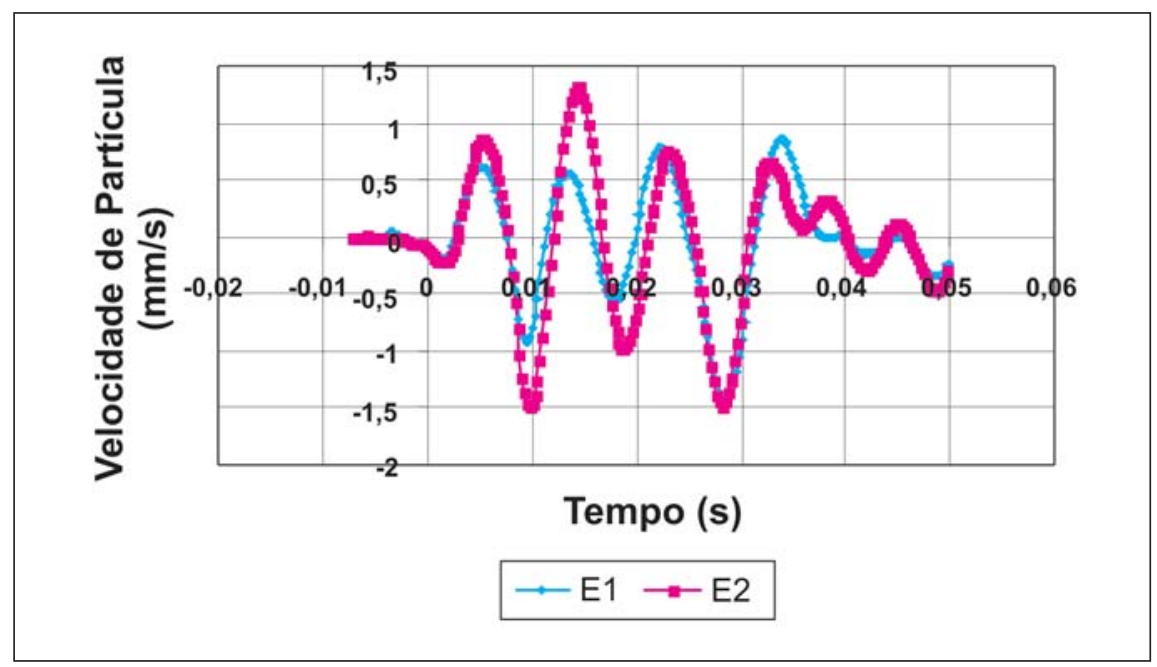

Figura 6 - Registros obtidos na componente transversal; eventos monitorados em 22/01/04 a partir de espoleta simples n. ${ }^{\circ} 8$.

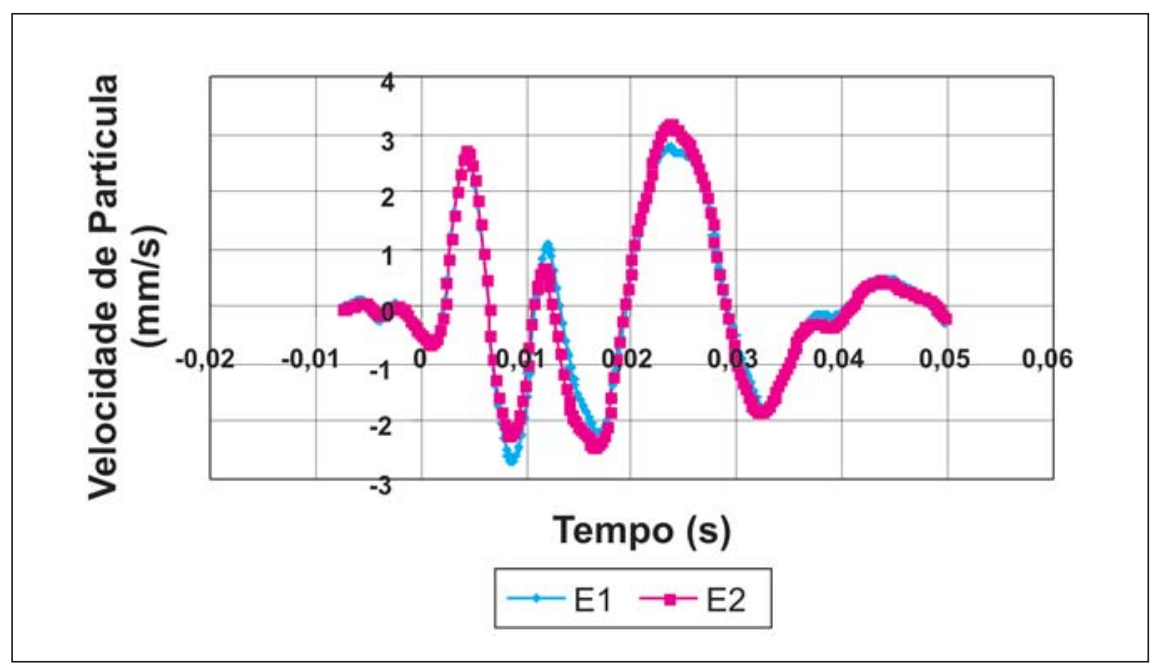

Figura 7- Registros obtidos na componente vertical; eventos monitorados em 22/01/04 a partir de espoleta simples n. ${ }^{\circ} 8$. 
Em uma primeira etapa (08/06/2004) foram realizados seis eventos que contemplaram montagens contendo acessórios de todos os tempos citados, sendo dois de cada tempo. Os resultados foram considerados satisfatórios. Os registros apresentaram as perturbações decorrentes da espoleta simples utilizada para a iniciação do evento individualizada em relação à do retardo, possibilitando a leitura direta dos tempos de retardo através do software BlastWare Series III na componente vertical. Nas demais componentes, considerou-se que a conjugação da pequena amplitude observada nos registros com intenso ruído de fundo, em relação às amplitudes obtidas, poderia comprometer os resultados. Atribuiu-se tal ruído de fundo às atividades desenvolvidas no entorno do local.

Posteriormente (19/06/2004) foram realizados 19 eventos, que contemplaram cinco montagens contendo retardos de 17 milissegundos, oito de 25 milissegundos e seis de 250 milissegundos, sendo utilizados os mesmos furos anteriormente feitos. As demais condições foram mantidas, inclusive na fixação do geofone. Os resultados obtidos foram similares àqueles obtidos na primeira etapa, inclusive em relação ao ruído de fundo, ainda que em menor intensidade, já que nessa ocasião inexistiam atividades em seu entorno (Figuras 12, 13, 14, 15, 16 e17).

Tendo em vista que tais ruídos de fundo dificultam, mesmo na componente vertical, a determinação precisa do instante em que iniciam os registros decorrentes das perturbações geradas, adotou-se, como referencial, na determinação do intervalo de tempo, os primeiros picos de cada perturbação. Os resultados obtidos encontram-se na Tabela 2.

O procedimento adotado para estimar os tempos de retardo de acessórios de detonação não elétricos redundou em resultados que apresentam consistência, necessitando, porém, de estudos mais aprofundados. Ensaios sistemáticos com a utilização conjunta de aparelhos de medição de velocidade de detonação

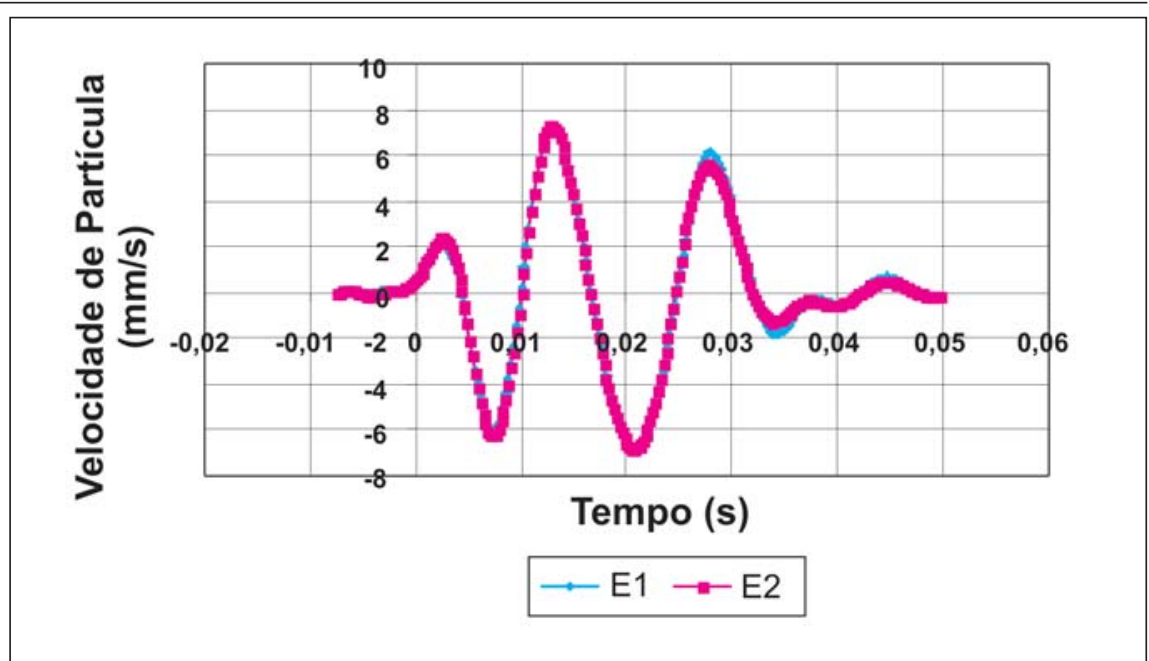

Figura 8 - Registros obtidos na componente longitudinal; eventos monitorados em 22/01/04 a partir de espoleta simples n. ${ }^{\circ} 8$.

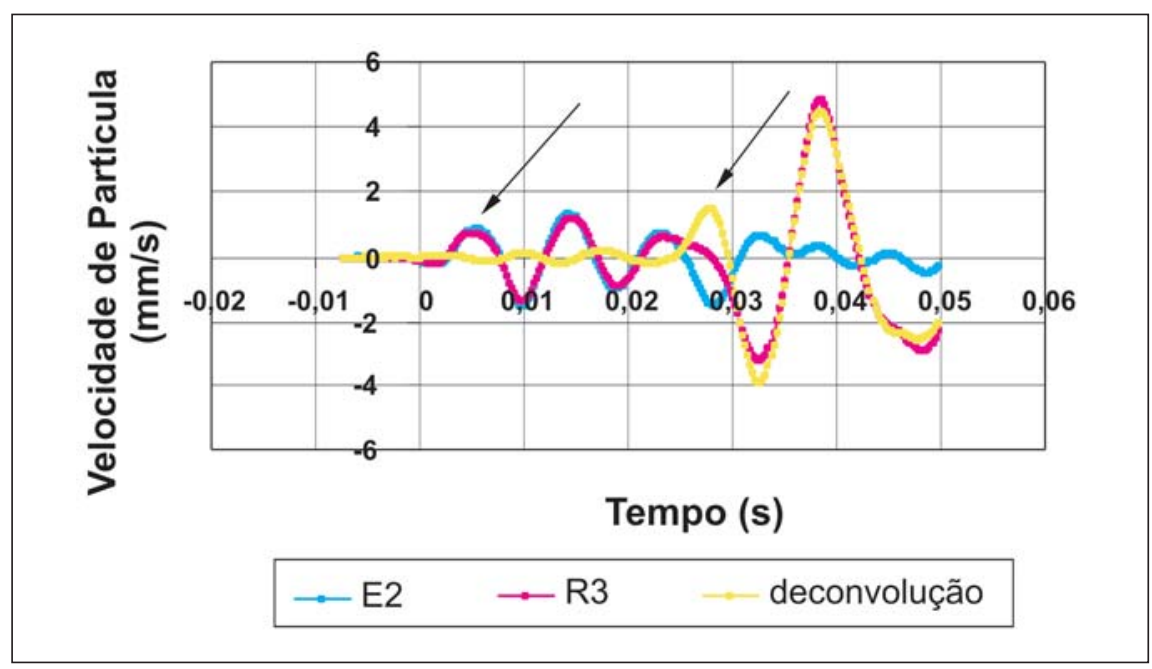

Figura 9 - Registros obtidos na componente transversal; eventos monitorados em 20/01/04 e representação do sinal "R3" deconvoluido do sinal "E2".

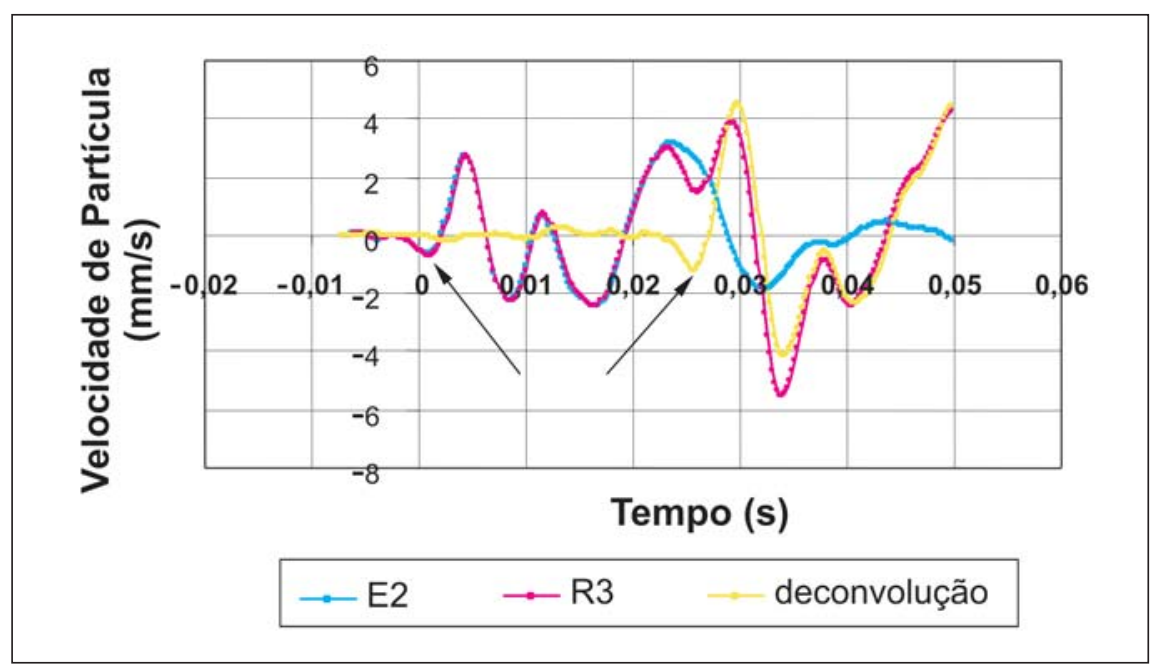

Figura 10 - Registros obtidos na componente vertical; eventos monitorados em 20/01/04 e representação do sinal "R3" deconvoluido do sinal "E2". 
poderão estimar precisão e deficiências, bem como as limitações na utilização dos sismógrafos de engenharia com essa finalidade. Demonstrada sua precisão pode vir a torna-se ferramenta no controle de qualidade de tais acessórios de detonação.

\section{Conclusões}

Consideradas as ressalvas quanto ao procedimento empregado na determinação dos tempos de retardo de tais acessórios de detonação, foram observados desvios que atingem, em relação aos tempos nominais, 22,35\% nos acessórios de 17 milissegundos, 17,20\% nos de 25 milissegundos e 4,12 \% naqueles de 250 milissegundos.

A partir de tais dados, o arranjo de elementos de retardo utilizados na iniciação da coluna de explosivos, com tempos nominais de 250 milissegundos, dispostos de forma a detonarem 2 minas instantaneamente, tem probabilidade de $62,5 \%$ de o fazer em intervalo igual ou superior a sete milissegundos. Em fogos configurados de modo que duas minas detonem individualmente, utilizando tais acessórios em conjunto com aqueles utilizados na ligação entre minas com tempos nominais de 17 milissegundos, existe a possibilidade de ocorrência de superposição de efeitos de detonação de

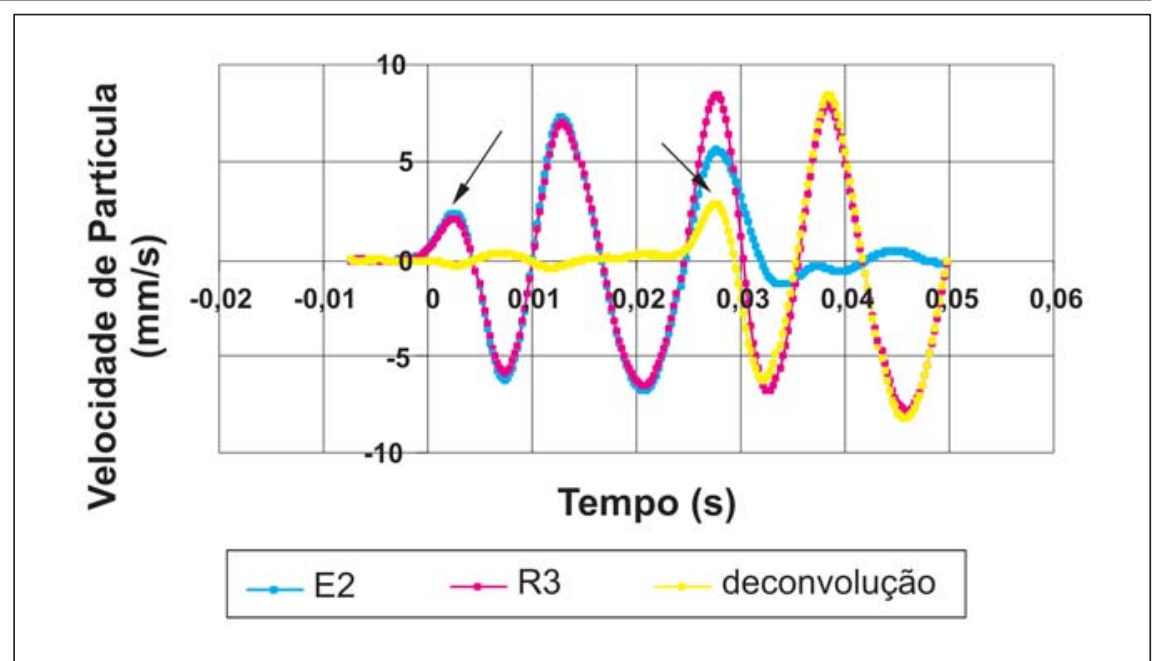

Figura 11 - Registros obtidos na componente longitudinal; eventos monitorados em 20/01/04 e representação do sinal "R3" deconvoluido do sinal "E2".

Tabela 1 - Tempos de retardo - meio de propagação: solo.

\begin{tabular}{c|c|c|c|c|c}
\hline Registro & Data & $\begin{array}{c}\text { Tempo } \\
\text { nominal } \\
\text { (ms) }\end{array}$ & $\begin{array}{c}\text { Tempo } \\
\text { observado } \\
\text { (ms)* }\end{array}$ & $\begin{array}{c}\text { Desvio } \\
\text { (ms) }\end{array}$ & $\begin{array}{c}\text { Desvio } \\
\text { (\%) }\end{array}$ \\
\hline R1 & $20 / 1 / 2004$ & 25 & 26,1 & 1,1 & 4,4 \\
\hline R2 & $20 / 1 / 2004$ & 25 & 20,9 & $-4,1$ & $-16,4$ \\
\hline R3 & $20 / 1 / 2004$ & 25 & 26,6 & 1,6 & 6,4 \\
\hline R4 & $22 / 1 / 2004$ & 25 & 25,1 & 0,1 & 0,4 \\
\hline R5 & $22 / 1 / 2004$ & 25 & 21,5 & $-3,5$ & -14 \\
\hline R6 & $22 / 1 / 2004$ & 25 & 24,9 & $-0,1$ & $-0,4$ \\
\hline
\end{tabular}

*Valores arredondados para a primeira casa decimal.

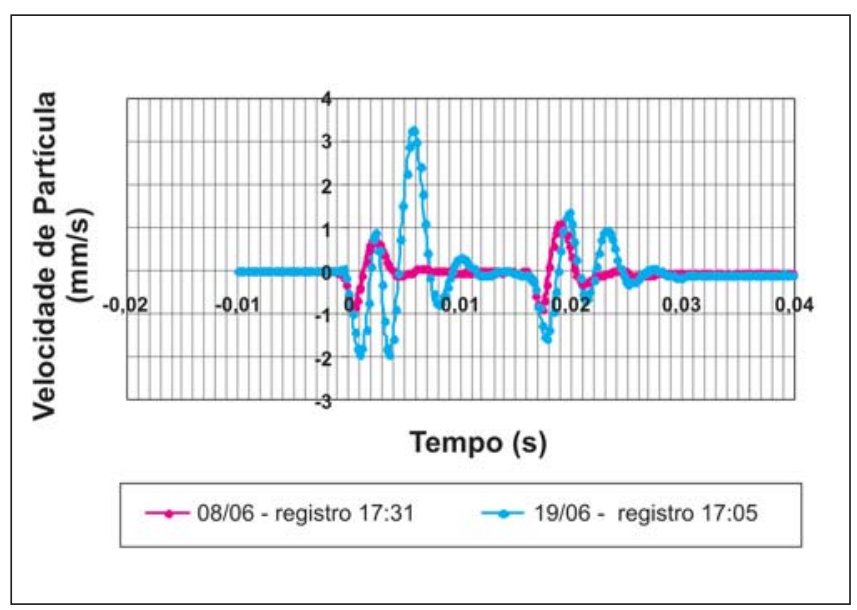

Figura 12 - Comparativo entre os registros 17:31, de 08/06/04 e 17:05 de 19/06/04, na componente vertical, a partir de retardos com tempos nominais de $17 \mathrm{~ms}$. Os valores observados foram de $16,8 \mathrm{~ms}$

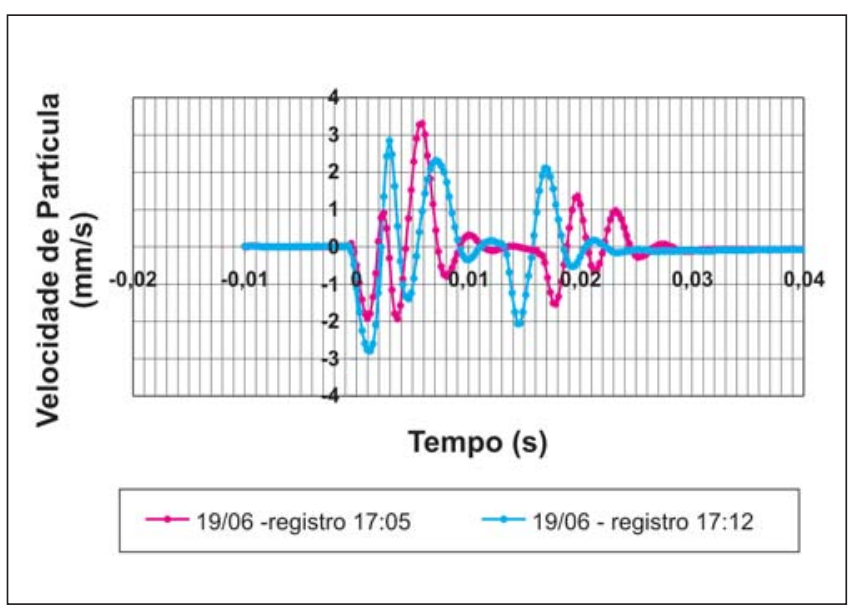

Figura 13 - Comparativo entre os registros 17:05 e 17:12 de $19 / 06 / 04$, na componente vertical, a partir de retardos com tempos nominais de $17 \mathrm{~ms}$. Os valores observados foram de $16,8 \mathrm{~ms}$ e de $13,2 \mathrm{~ms}$, respectivamente. 


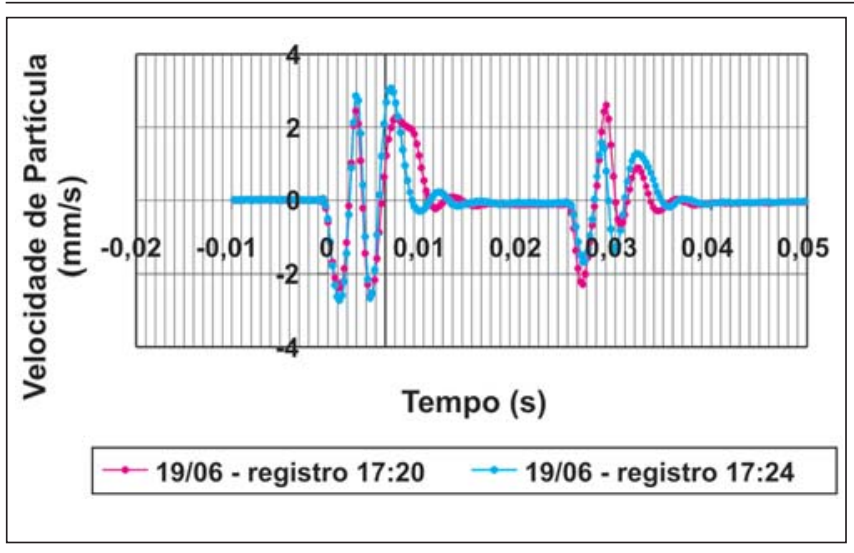

Figura 14 - Comparativo entre os registros 17:20 e 17:24 de 19/06/04, na componente vertical, a partir de retardos com tempos nominais de $25 \mathrm{~ms}$. Os valores observados foram de $25,4 \mathrm{~ms}$.

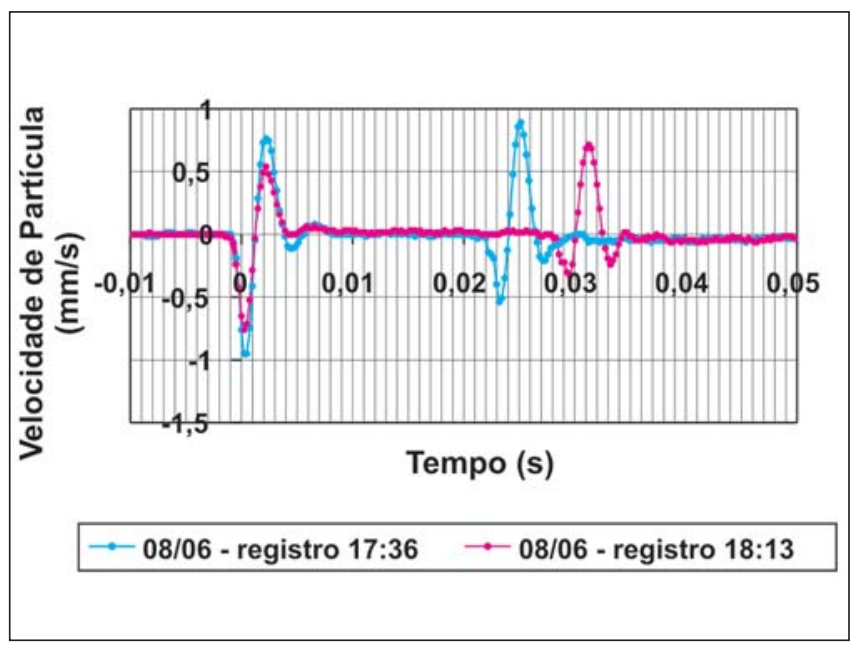

Figura 15 - Comparativo entre os registros 17:36 e 18:13 de 08/06/04, na componente vertical, a partir de retardos com tempos nominais de $25 \mathrm{~ms}$. Os valores observados foram de 22,9 ms e $29,3 \mathrm{~ms}$, respectivamente.

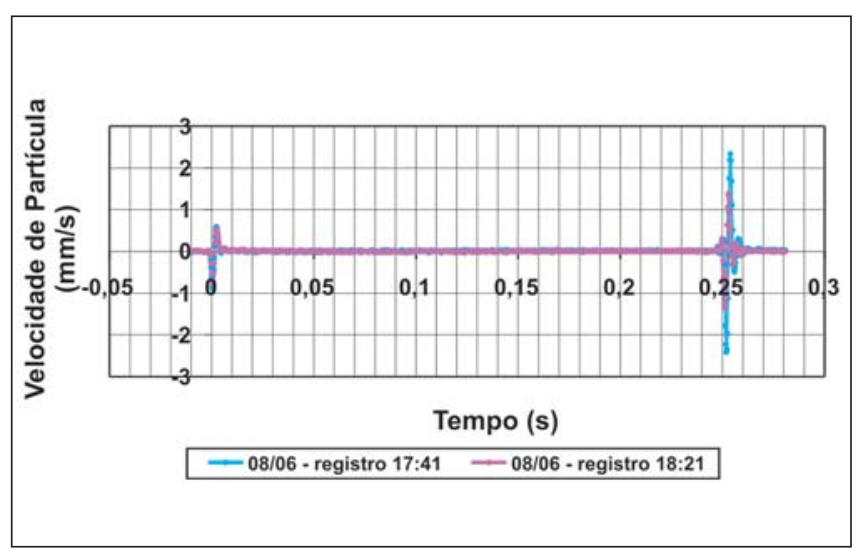

Figura 16 - Comparativo entre os registros 17:41 e 18:21 de 08/06/04, na componente vertical, a partir de retardos com tempos nominais de $250 \mathrm{~ms}$. Os valores observados foram de $251,4 \mathrm{~ms}$ e $250,9 \mathrm{~ms}$, respectivamente.

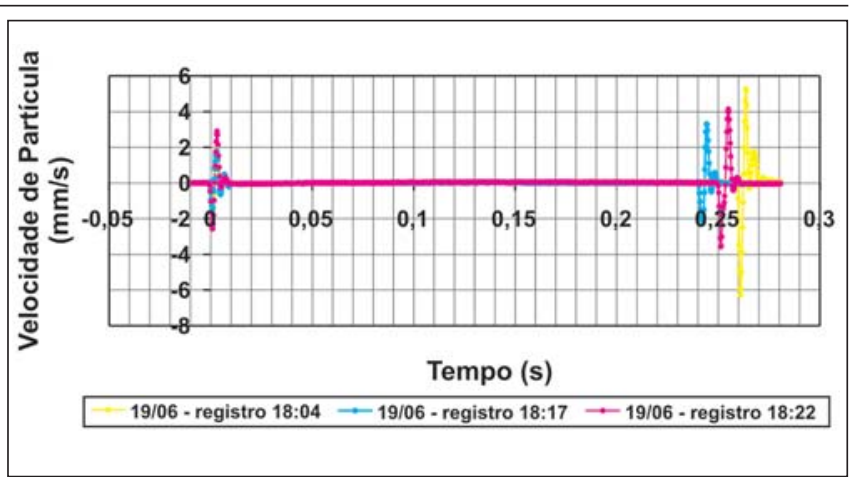

Figura 17 - Comparativo entre os registros 18:04, 18:17 e 18:22 de 19/06/04, na componente vertical, a partir de retardos com tempos nominais de $250 \mathrm{~ms}$. Os valores observados foram de $260,3 \mathrm{~ms}, 241,7 \mathrm{~ms}$ e $250,5 \mathrm{~ms}$, respectivamente.

Tabela 2 - Tempos de retardo - meio de propagação: maciço basáltico.

\begin{tabular}{c|c|c|c|c|c}
\hline Data & Hora & $\begin{array}{c}\text { Tempo } \\
\text { nominal } \\
\text { (ms) }\end{array}$ & $\begin{array}{c}\text { Tempo } \\
\text { observado } \\
(\mathbf{m s})^{*}\end{array}$ & $\begin{array}{c}\text { Desvio } \\
\text { (ms) }\end{array}$ & $\begin{array}{c}\text { Desvio } \\
\text { (\%) }\end{array}$ \\
\hline $8 / 6 / 2004$ & $17: 31$ & 17 & 16,8 & $-0,2$ & $-1,18$ \\
\hline $8 / 6 / 2004$ & $17: 55$ & 17 & 14,4 & $-2,6$ & $-15,29$ \\
\hline $19 / 6 / 2004$ & $17: 02$ & 17 & 13,7 & $-3,3$ & $-19,41$ \\
\hline $19 / 6 / 2004$ & $17: 05$ & 17 & 16,8 & $-0,2$ & $-1,18$ \\
\hline $19 / 6 / 2004$ & $17: 08$ & 17 & 14,9 & $-2,1$ & $-12,35$ \\
\hline $19 / 6 / 2004$ & $17: 12$ & 17 & 13,2 & $-3,8$ & $-22,35$ \\
\hline $19 / 6 / 2004$ & $17: 15$ & 17 & 16,1 & $-0,9$ & $-5,29$ \\
\hline $8 / 6 / 2004$ & $17: 36$ & 25 & 22,9 & $-2,1$ & $-8,4$ \\
\hline $8 / 6 / 2004$ & $18: 13$ & 25 & 29,3 & 4,3 & 17,2 \\
\hline $19 / 6 / 2004$ & $17: 20$ & 25 & 25,4 & 0,4 & 1,6 \\
\hline $19 / 6 / 2004$ & $17: 24$ & 25 & 25,4 & 0,4 & 1,6 \\
\hline $19 / 6 / 2004$ & $17: 34$ & 25 & 26,4 & 1,4 & 5,6 \\
\hline $19 / 6 / 2004$ & $17: 36$ & 25 & 27,1 & 2,1 & 8,4 \\
\hline $19 / 6 / 2004$ & $17: 39$ & 25 & 23,4 & $-1,6$ & $-6,4$ \\
\hline $19 / 6 / 2004$ & $17: 44$ & 25 & 22,9 & $-2,1$ & $-8,4$ \\
\hline $19 / 6 / 2004$ & $17: 50$ & 25 & 23,9 & $-1,1$ & $-4,4$ \\
\hline $19 / 6 / 2004$ & $18: 31$ & 25 & 27,6 & 2,6 & 10,4 \\
\hline $8 / 6 / 2004$ & $17: 41$ & 250 & 251,4 & 1,4 & 0,56 \\
\hline $8 / 6 / 2004$ & $18: 21$ & 250 & 250,9 & 0,9 & 0,36 \\
\hline $19 / 6 / 2004$ & $18: 00$ & 250 & 248,8 & $-1,2$ & $-0,48$ \\
\hline $19 / 6 / 2004$ & $18: 04$ & 250 & 260,3 & 10,3 & 4,12 \\
\hline $19 / 6 / 2004$ & $18: 08$ & 250 & 259,3 & 9,3 & 3,72 \\
\hline $19 / 6 / 2004$ & $18: 13$ & 250 & 242 & -8 & $-3,2$ \\
\hline $19 / 6 / 2004$ & $18: 17$ & 250 & 241,7 & $-8,3$ & 3,32 \\
\hline $19 / 6 / 2004$ & $18: 22$ & 250 & 250,5 & 0,5 & 0,2 \\
\hline$V / 0195$ & & \\
\hline
\end{tabular}

*Valores arredondados para a primeira casa decimal. 
minas e mesmo a de inversão na seqüência de detonação em relação àquela esperada. Estas considerações indicam a necessidade de, quando da elaboração de planos de fogo, atentar-se para a ocorrência e magnitude de tais desvios, por suas implicações: ambientais, que incluem aspectos relativos à segurança, e econômicas.

Como conseqüência, pode-se prever uma maior possibilidade na ocorrência de ultralançamentos, níveis de vibração superiores ao previsto, fragmentação e lançamento inadequados, poden- do, ainda, causar danos excessivos ao maciço remanescente, com suas conseqüências aos desmontes subseqüentes.

Tendo em vista a ausência de normatização nacional referente a explosivos e acessórios de detonação, cabe ao usuário a adoção de medidas de controle de qualidade quando da aquisição desses produtos, uma vez que ele suportará os ônus decorrentes de sua utilização.

\section{Referência bibliográfica}

DALLORA NETO, C. Análise das vibrações resultantes do desmonte de rocha em mineração de calcário e argilito posicionada junto à área urbana de Limeira (SP) e sua aplicação para minimização de impactos ambientais. Rio Claro: Instituto de Geociências e Ciências Exatas da Universidade Estadual Paulista, 2004. 82p. (Dissertação de Mestrado).

Artigo recebido em 30/03/2007 e aprovado em 01/12/2007.

\title{
Descubra as muitas informações da:
}

\author{
Geologia, Mineração, \\ Metalurgia \& Materiais
}

e Engenharia Civil.
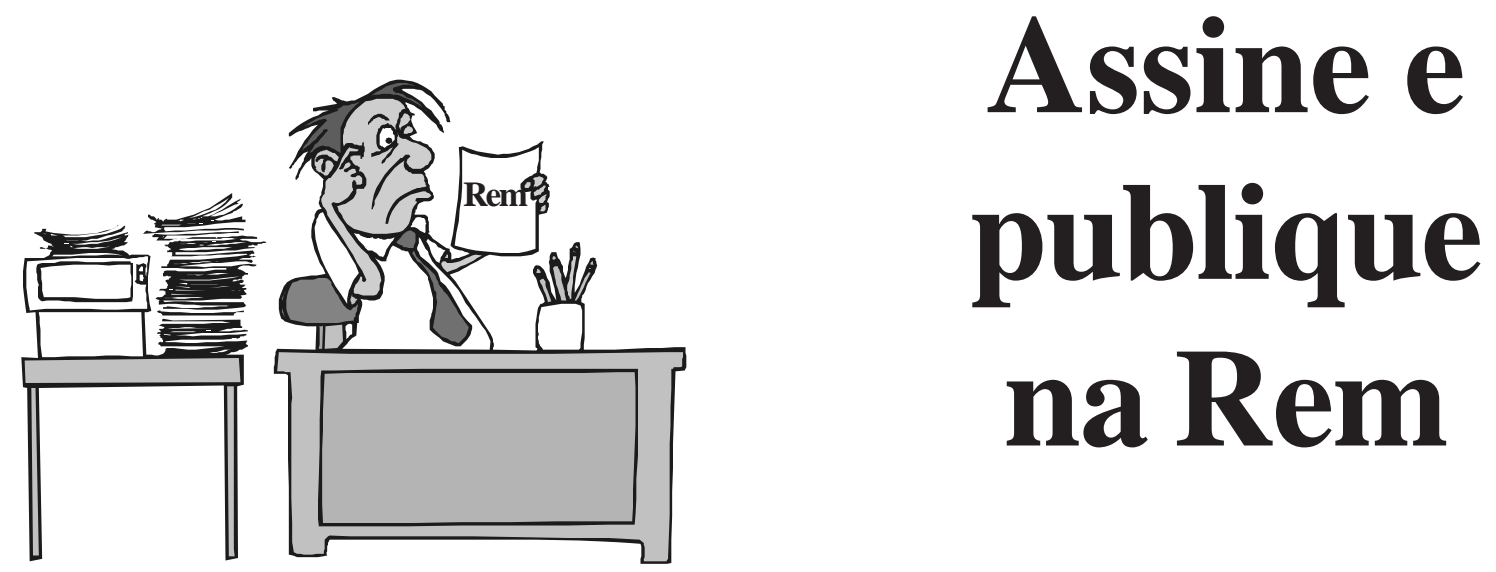

Conheça o nosso novo site: WWW.rem.com.br 